\title{
O meio ambiente e a proteção da saúde humana
}

\section{The environment and the protection of human health}

\author{
Paulo César Nunes da Silva
}

\begin{abstract}
RESUMO:
O presente ensaio analisará a proteção da saúde humana por meio do arcabouço jurídico protetivo do meio ambiente. Com o estabelecimento das bases do trabalho focado no direito à saúde humana, assim como a análise do meio ambiente e seus aspectos jurídicos nacionais e internacionais, se terá o ponto de partida do trabalho, culminando com a premissa de que o meio ambiente e a saúde são temas indissociáveis, principalmente quando da atuação dos Princípios de Direito Ambiental da Prevenção e Precaução, além do Princípio do não retrocesso social em matéria ambiental.
\end{abstract}

\section{PALAVRAS-CHAVE:}

Meio Ambiente, Princípios de Direito Ambiental, Saúde Humana.

\begin{abstract}
:
This essay will analyze the protection of human health through the protective legal framework of the environment. This study will be the starting point with the establishment of the bases of the work focused on the right to human health, as well as the analysis of the environment and its national and international legal aspects, culminating with the assumption that the environment and health are inseparable issues, mainly when the performance of the Principles of Environmental Law of Prevention and Precaution, besides the Principle of the non-social regression in environmental subject.
\end{abstract}

\section{KEYWORDS:}

Environment, Principles of Environmental Law, Human Health.

\footnotetext{
${ }^{1}$ Professor da Universidade Estadual do Mato Grosso do Sul/MS. Doutorando em Direito do Estado pela Universidade de São Paulo (Dinter USP/UFMS 2018/20). Mestre em Direito Processual e Cidadania pela Universidade Paranaense (Unipar - 2013). Bacharel em Direito pelo Centro Universitário da Grande Dourados (Unigran - 2006). Especialista em Direito Civil e Processual. Especialista em Direitos Humanos e Cidadania. Especialista em Gestão Pública Municipal. MBA em Gestão da Saúde.
} 


\section{INTRODUÇÃO}

A partir de uma visão interdependente entre o estudo do meio ambiente e da proteção da saúde humana, a pesquisa pretende discorrer sobre as bases legal e doutrinária de ambos, assim como a utilização de instrumentos de proteção capazes de oferecer maior e mais efetiva proteção ao direito humano fundamental à saúde.

Na sequência, o trabalho fará a análise detida dos aspectos do meio ambiente, com a apresentação das primeiras linhas que conduzem o tema, os aspectos da ética ambiental, seus antecedentes históricos, assim como a propedêutica que rege o espectro jurídico protetivo da matéria.

Noutro ponto, a abordagem da saúde em termos de conceituação, histórico e demais noções introdutórias, assim como o fenômeno da constitucionalização desse direito no Brasil em 1.988 é aspecto fundamental para firmar bases sólidas a despeito das conclusões que se pretende.

Igualmente, promover a interface de ambos conceitos (meio ambiente e saúde humana), de modo a destacar a interdisciplinaridade pertinente entre os temas, assim como a possibilidade de maior proteção aos direitos analisados e protegidos conjuntamente é preceito que se busca com o ensaio.

Dalmo Dallari (DALLARI, 1998. p. 56) assevera que "como já aconteceu com outros direitos fundamentais, em outras épocas, na segunda metade do século vinte foi reconhecido e vem ganhando ênfase o direito humano ao meio ambiente saudável (grifou-se)", e desse reconhecimento justamente que advém a interdependência dos conceitos de meio ambiente e saúde humana, onde um subsidiará a proteção do outro!

Na mesma senda, vez que decorrente do contrato social entabulado nos moldes de Rousseau, a sociedade deve exigir ações que visem a manutenção de suas condições de vida, tendo em vista a competência que delegaram a seus governos. Disso é que se vislumbra a 
“emergência da cidadania social" e do cidadão cosmopolita, efeitos da globalização de movimentos sociais humanistas, preocupados com a sustentabilidade do mundo"2.

Imprescindível destacar que a consciência de preservação ambiental foi realmente despertada, a partir da Conferência das Nações Unidas sobre o Ambiente Humano, em Estocolmo (Suécia), em 1972, onde foram estabelecidos princípios básicos de um novo ramo do direito: o Direito Ambiental, despertar esse que foi replicado em nossa Carta Magna de 1.988 .

Igualmente digno, justo e correlato ao direito do meio ambiente saudável é a manutenção da saúde dos seres humanos, pelo que numa regra lógica (silogismo) dependerá da manutenção da higidez de todo o meio!

Assim como no âmbito do meio ambiente, vestibular foi a Constituição Federal de 1.988 ao prever um rol completo de dispositivos protetores e garantidores do direito à saúde, os quais, apesar de num primeiro momento foram (ou são) tratados como meras normas programáticas, ou seja, não exercitáveis de imediato pelos cidadãos, se constituem como Direito Humano Fundamental. Portanto, essa extensa previsão nos faz crer verdadeiramente que se trata de um Direito Fundamental, cuja proteção é dever de todos, sobretudo do Poder Público, sendo a Constituição de 1.988 um importante marco inaugural do direito à saúde.

Sabendo-se que em diversos momentos da descrição dos conceitos do meio ambiente e do direito ambiental se trata da dignidade da pessoa humana, garantia do direito fundamental à vida, essencialidade à sadia qualidade de vida, entre outros vários momentos em que as matérias se tocam numa clara interseção, necessário, portanto tecer maiores e mais profundos comentários acerca da interface: proteção à saúde por meio de um meio ambiente equilibrado,

\footnotetext{
${ }^{2}$ DALLARI. Op Cit. p. 56-57: “As preocupações com a pureza ambiental como algo fundamental e permanente para a humanidade tornaram-se explícitas na década de sessenta. Foi demonstrada então vários fatores que provocam o desequilíbrio dos elementos da natureza e criam exaustão de recursos naturais. A enumeração desses fatores, foi feita por um especialista inglês, David Hughes, inclui o aumento das populações, a ocorrência de altos níveis de poluição, a interferência humana nas populações animais e na paisagem, o grande aumento do número de automóveis e a consequente intensificação do uso de combustíveis poluidores, além de diversas modalidades de destruição dos recursos naturais... Em consequência desses estudos e de sua divulgação, foi surgindo uma nova mentalidade e cresceu rapidamente o número dos que passaram a reconhecer que a proteção do meio ambiente era parte da defesa do patrimônio natural da humanidade e que, em consequência, aquela proteção deveria estar entre os direitos humanos fundamentais." (grifou-se).
} 
principalmente com a análise da principiologia que cerca o direito ambiental, e sua utilização para a garantia da plena saúde humana.

A esse respeito, lapidar será a análise específica de todo conjunto principiológico do direito ambiental e dos direitos humanos, com ênfase ao Princípio do não retrocesso social em matéria ambiental, que se apresenta como importante instrumento protetivo previsto na disciplina dos direitos humanos fundamentais, estando no foco das análises do direito ambiental mais recentemente, tratado inclusive como o Princípio do não retrocesso ambiental, devendo, portanto, ser melhor estudado e compreendido, já que se denota como fundamental para que a saúde humana seja efetivamente protegida com o viés dos direitos humanos.

\section{O MEIO AMBIENTE}

Relevante ao debate é a análise do meio ambiente e seus aspectos conceituais, os quais convencionou-se chamar de primeiras linhas, com relevante destaque à consciência ecológica despertada no mundo em décadas mais recentes.

Quanto ao conceito de meio ambiente a maioria dos doutrinadores concordam que se trata de uma redundância, pois "meio" é algo que está no centro, e "ambiente" diz respeito ao lugar de seres vivos, por isso pelo fato de ambiente ser parte de meio, haveria certa redundância, no entanto, mesmo assim, por ser o termo mais empregado pela legislação, jurisprudência e pela população em geral, se tornou o mais usual e é como se tratará dele no presente ensaio.

Destaque ao conceito legal de meio ambiente, trazido pelo artigo $3^{\circ}$, I, da Lei $n^{\circ}$ 6.938/81, como sendo "o conjunto de condições, leis, influências, alterações e interações de ordem física, química e biológica que permite, abriga e rege a vida em toda as suas formas".

Necessário também se trazer um conceito doutrinário ao meio ambiente, o de José Afonso da Silva, que completa o conceito legal entoando dizendo que se trata da "interação do conjunto de elementos naturais, artificiais e culturais que propiciem o desenvolvimento equilibrado da vida em todas as suas formas..." (SILVA, 2003, p. 19), ao qual, por ser um 
apêndice mais recente, se acresce o meio ambiente do trabalho nesse conceito, a fim de complementá-lo.

Visto o conceito da disciplina, traz-se a informação que desde os primórdios da sociedade tem-se que o meio ambiente é tema relevante, no entanto em seu viés natural, tendo em vista o atendimento das necessidades de sobrevivência da raça humana.

À fase plena de proteção ao meio ambiente deu-se o nome de fase holística, onde colabora com a narrativa o ilustre estudioso Capra:

\begin{abstract}
"O novo paradigma pode ser chamado de uma visão de mundo holística, que concebe o mundo como um todo integrado, e não como uma coleção de partes dissociadas. Pode também ser denominado visão ecológica, se o termo "ecológica" for empregado num sentido muito mais amplo e mais profundo que o usual. A percepção ecológica profunda reconhece a interdependência fundamental de todos os fenômenos, e o fato de que, enquanto indivíduos e sociedades, estamos todos encaixados nos processos cíclicos da natureza (e, em última análise, somos dependentes desses processos)" (CAPRA, 2006. p. 25)
\end{abstract}

Atualmente o tema se debruça sobre as mais diversas narrativas, dentre os quais se destacam os resíduos nucleares, a disposição de lixo químico, o lixo doméstico, hospitalar, e industrial de forma inadequada, as queimadas, o desperdício de recursos naturais não renováveis, o efeito estufa, o desmatamento indiscriminado, a contaminação dos rios, a degradação do solo pela mineração e agrotóxicos, a aceleração industrial sem planejamento, a urbanização desordenada, e a caça e pesca predatórias. Daí é que surge a necessidade de conscientização dos seres humanos acerca da relação homem x ambiente, e seu convívio harmonizado.

No Brasil o primeiro passo foi dado com a Constituição Federal de 1.988, especificamente no artigo 225, o qual se transcreve na íntegra:

"Art. 225. Todos têm direito ao meio ambiente ecologicamente equilibrado, bem de uso comum do povo e essencial à sadia qualidade de vida, impondo-se ao poder público e à coletividade o dever de defendê-lo e preservá-lo para as presentes e futuras gerações.

$\S 1^{\circ}$ Para assegurar a efetividade desse direito, incumbe ao poder público:

I - preservar e restaurar os processos ecológicos essenciais e prover o manejo ecológico das espécies e ecossistemas;

II - preservar a diversidade e a integridade do patrimônio genético do País e fiscalizar as entidades dedicadas à pesquisa e manipulação de material genético;

III - definir, em todas as unidades da Federação, espaços territoriais e seus 
componentes a serem especialmente protegidos, sendo a alteração e a supressão permitidas somente através de lei, vedada qualquer utilização que comprometa a integridade dos atributos que justifiquem sua proteção;

IV - exigir, na forma da lei, para instalação de obra ou atividade potencialmente causadora de significativa degradação do meio ambiente, estudo prévio de impacto ambiental, a que se dará publicidade;

V - controlar a produção, a comercialização e o emprego de técnicas, métodos e substâncias que comportem risco para a vida, a qualidade de vida e o meio ambiente;

VI - promover a educação ambiental em todos os níveis de ensino e a conscientização pública para a preservação do meio ambiente;

VII - proteger a fauna e a flora, vedadas, na forma da lei, as práticas que coloquem em risco sua função ecológica, provoquem a extinção de espécies ou submetam os animais a crueldade.

$\S 2^{\circ}$ Aquele que explorar recursos minerais fica obrigado a recuperar o meio ambiente degradado, de acordo com solução técnica exigida pelo órgão público competente, na forma da lei.

$\S 3^{\circ}$ As condutas e atividades consideradas lesivas ao meio ambiente sujeitarão os infratores, pessoas físicas ou jurídicas, a sanções penais e administrativas, independentemente da obrigação de reparar os danos causados.

§ $4^{\circ}$ A Floresta Amazônica brasileira, a Mata Atlântica, a Serra do Mar, o Pantanal Mato-Grossense e a Zona Costeira são patrimônio nacional, e sua utilização far-se-á, na forma da lei, dentro de condições que assegurem a preservação do meio ambiente, inclusive quanto ao uso dos recursos naturais.

$\S 5^{\circ}$ São indisponíveis as terras devolutas ou arrecadadas pelos Estados, por ações discriminatórias, necessárias à proteção dos ecossistemas naturais.

$\S 6^{\circ}$ As usinas que operem com reator nuclear deverão ter sua localização definida em lei federal, sem o que não poderão ser instaladas.

$\S 7^{\circ}$ Para fins do disposto na parte final do inciso VII do $\S 1^{\circ}$ deste artigo, não se consideram cruéis as práticas desportivas que utilizem animais, desde que sejam manifestações culturais, conforme o $\S 1^{\circ}$ do art. 215 desta Constituição Federal, registradas como bem de natureza imaterial integrante do patrimônio cultural brasileiro, devendo ser regulamentadas por lei específica que assegure o bem-estar dos animais envolvidos."

Outro fator relevante acerca do meio ambiente é a educação ambiental, que igualmente foi inserida no bojo constitucional, no artigo $225, \S 1^{\circ}$, VI, supratranscrito, e devidamente regulamentada através da Lei $\mathrm{n}^{\circ}$ 9.795/99, que instituiu o Plano Nacional da Educação Ambiental.

Importante se destacar que na educação ambiental se tem a fundamentação da ética ambiental, que é o estudo dos juízos de valor das condutas humanas em relação ao meio ambiente, de onde advirá a compreensão de que ser humano tem a necessidade de preservar o meio ambiente para garantir a sua própria sobrevivência, e isso poderá ser atingido caso seja exercitada a cidadania, como caminho para a preservação ambiental, isso, por óbvio, por meio 
da educação ambiental, a despeito do que já foi destacado por Dalmo Dallari alhures acerca da “emergência da cidadania social”, e a consequente sustentabilidade global.

Assim, a Constituição Federal destinou seu artigo 225 para tutelar o direito de todos a um meio ambiente ecologicamente equilibrado, sendo a preservação ambiental um corolário da garantia do direito fundamental à vida, matriz de todos os demais direitos, passando a ser um valor social constitucionalmente reconhecido, e é justamente nesse ponto que o tema do ensaio começa a fazer mais sentido, ou seja, a saúde humana somente pode ser obtida em sua forma plena desde que respeitado o direito primário do equilíbrio no meio em que os seres humanos habitam!

Portanto, sendo o meio ambiente considerado um patrimônio público essencial à sadia qualidade de vida, cabendo ao poder público e à coletividade o dever de defendê-lo e preserválo, tem-se que a saúde humana, igualmente, é um dever de todos, e o atingimento desse direito na plenitude pode ser muito mais rápido e efetivo caso sejam utilizadas as normas protetivas do meio ambiente, sobretudo a base principiológica.

E não por um acaso, a essencialidade e importância do meio ambiente é retratada diante dos diversos são os antecedentes histórico da disciplina, dentre os quais destaque à Bíblia Sagrada (no ponto em que prega divindade da natureza, o Código de Hamurabi (2.050 aC), a Magna Charta (1.215 - Rei João Sem Terra), a Carta de tribo indígena nos Estados Unidos (Cacique Seatle - 1.854), a criação da Organização da Nações Unidas (1945 - PNUMA Programa das Nações Unidas para o Meio Ambiente), a Declaração Universal dos Direitos Humanos (1948), a Declaração de Estocolmo (1972 - Suécia), a Conferência do Rio (ECO 92 - Cúpula da Terra), além do avanços nos MDL - Mecanismos de Desenvolvimento Limpo, e diversos outros acordos e tratados internacionais.

Especificamente em relação ao Direito Ambiental, convém dizer que é disciplina relativamente nova no direito, e anteriormente era parte integrante do Direito Administrativo, que adquiriu autonomia, sobretudo após a edição da Lei n ${ }^{\circ}$ 6.938/81 (Lei da Política Nacional do Meio Ambiente), e atualmente encontra-se inserida nos vários currículos nacionais, inclusive com previsão constitucional, tendo autonomia legal, doutrinária e jurisprudencial, consistindo no principal meio de proteção ao meio ambiente, a esse respeito veja-se o que diz o Ministro Herman Benjamin: 


\begin{abstract}
"Somente a partir de 1981, com a promulgação da Lei nº 6.938/81 (Lei da Política Nacional do Meio Ambiente), ensaiou-se o primeiro passo em direção a um paradigma jurídico-econômico que holisticamente tratasse e não maltratasse a terra, seus arvoredos e os processos ecológicos essenciais a ela associados. Um caminhar incerto e talvez insincero a princípio, em pleno regime militar, que ganhou velocidade com a democratização em 1985 e recebeu extraordinária aceitação na Constituição de 1988.” (BENJAMIN, In: CANOTILHO; LEITE, 2007. p. 57/58)
\end{abstract}

Fiel à proposta do ensaio, neste ponto necessário destacar a principiologia que cerca o direito ambiental, pois é justamente deste meio que se utilizará o suporte necessário à afirmação e a plenitude protetiva da saúde humana.

Os princípios variam de acordo com os autores que se estuda, onde se resumiu, portanto, não se exaurindo a temática, da seguinte maneira:

a) princípio do direito humano: este princípio é decorrente da Declaração de Estocolmo, artigo $1^{\circ}$, que prevê que os seres humanos devem constituir o centro das preocupações relacionadas com o ecodesenvolvimento:

Princípio 1: O homem tem o direito fundamental à liberdade, à igualdade e ao desfrute de condições de vida adequadas em um meio ambiente de qualidade tal que lhe permita levar uma vida digna e gozar de bem-estar, tendo a solene obrigação de proteger e melhorar o meio ambiente para as gerações presentes e futuras. A este respeito, as políticas que promovem ou perpetuam o apartheid, a segregação racial, a discriminação, a opressão colonial e outras formas de opressão e de dominação estrangeira são condenadas e devem ser eliminadas.

b) princípio do desenvolvimento sustentável: nesse princípio tem-se que sempre deve se conciliar o meio ambiente com o desenvolvimento socioeconômico, isso a fim de melhorar a qualidade de vida do homem (nos aspectos socioeconômicos), e se traduz no chamado meio ambiente ecologicamente equilibrado ou ecodesenvolvimento;

c) princípio democrático: do referido princípio advém a garantia que assegura ao cidadão a possibilidade de participação nas políticas públicas ambientais, isso nas esferas administrativa (comitês, conselhos, etc.) e processual (proposição de ações populares, ações civis públicas e etc.);

d) princípio da preservação, precaução e/ou cautela: esse princípio é decorrente do Princípio 15 da ECO/92, e aduz que quando houver ameaça de danos sérios ou irreversíveis ao meio ambiente, deverá o Estado atuar conforme esse princípio, preventivamente, a fim de prevenir o dano: 
Princípio 15: Para que o ambiente seja protegido, será aplicada pelos Estados, de acordo com as suas capacidades, medidas preventivas. Onde existam ameaças de riscos sérios ou irreversíveis não será utilizada a falta de certeza científica total como razão para o adiamento de medidas eficazes em termos de custo para evitar a degradação ambiental.

e) princípio do equilíbrio: segundo tal princípio devem ser "pesadas" todas as intervenções no meio ambiente, buscando sempre aquela que seja globalmente positiva e menos danosa ao meio ambiente (sustentabilidade);

f) princípio do limite: esse princípio é a materialização da limitação por parte da Administração quanto à emissão de partículas, ruídos e presença de corpos estranhos no meio ambiente, a fim de evitar atividade poluidora. Não se consiste numa invasão do Estado na liberdade dos nacionais, mas sim em limitações legais/regulamentares às atividades potencialmente poluidoras e consequentemente danosas ao meio ambiente e seus usufrutuários; e

g) princípio do poluidor-pagador: esse princípio decorre do Princípio 13 da ECO/92, no qual tem-se que quem polui (no Brasil pessoas físicas e/ou jurídicas) deve pagar pelo dano que causou ao meio ambiente, da forma mais ampla possível. Desdobramento desse princípio é a própria regra de responsabilização civil do poluidor, que independe de culpa provada, ou seja, é uma modalidade de responsabilidade objetiva:

Princípio 13: Os Estados deverão elaborar legislação nacional relativa à responsabilidade civil e à compensação das vitimas da poluição e de outros prejuízos ambientais. Os Estados deverão também cooperar de um modo expedito e mais determinado na elaboração de legislação internacional adicional relativa à responsabilidade civil e compensação por efeitos adversos causados por danos ambientais em áreas fora da sua área de jurisdição, e causados por atividades levadas a efeito dentro da área da sua jurisdição de controle.

Ainda como forma de apresentar a essência da disciplina meio ambienta, assim como seu desdobramento jurídico, o direito ambiental, salutar destacar que se implementou no Brasil uma Política Nacional do Meio Ambiente, por meio da Lei $\mathrm{n}^{\circ}$ 6.938/81, sendo a referida lei ambiental mais importante depois da Constituição Federal de 1.988 (lei essa que foi devidamente recepcionada/alterada pela referida Constituição).

Essa Política visa dar efetividade ao princípio-chave do artigo 225 da Carta Magna de 1.988, Paulo de Bessa Antunes "vislumbra a influência da National Environmental Policy Act sobre esse sistema, que tem como finalidade estabelecer uma rede de agências governamentais, nos três níveis da federação, com o objetivo de implementar a Política Nacional do Meio 
Ambiente" (ANTUNES, 2000. p. 66), sendo portanto também um instrumento essencial de proteção à saúde humana, já que fora concebida para dar maior e efetiva proteção ao meio ambiente, protegendo consequentemente a higidez humana.

Esses foram os principais pontos do maio ambiente, onde foram apresentadas as noções introdutórias sobre a temática, a partir do que se pode perceber que de fato o meio ambiente equilibrado é essencial à proteção da saúde humana. Ainda assim, necessário avençar nos demais conceitos para firmar as bases sólidas na busca dessa conclusão!

\section{A TUTELA INTERNACIONAL DO MEIO AMBIENTE}

Não é apenas no campo nacional que o meio ambiente, e consequentemente o direito ambiental pode contribuir para a proteção da saúde humana, mas também no campo do direito internacional, onde as bases convencionais consistem em importantes instrumentos de proteção.

Assim, sabendo-se da existência de uma tutela internacional do meio ambiente, salutar conhecer o conceito de meio ambiente internacional, que surge de diversos documentos firmados entre os países da comunidade mundial (acordos e tratados internacionais), de onde justamente provém esse novel ramo do direito, o direito internacional do meio ambiente, onde tratados, convenções, declarações, recomendações, diretrizes, regras e normas protetivas do meio ambiente são utilizados pelos referidos países acreditantes.

É, portanto, o direito internacional do meio ambiente o conjunto de regras e princípios que criam obrigações e direitos de natureza ambiental para os Estados, as organizações intergovernamentais e os indivíduos.

Consistem como fontes dessa tutela internacional os tratados e convenções internacionais, os atos das organizações intergovernamentais, os costumes internacionais, os princípios gerais do direito, a doutrina internacional, assim como a jurisprudência das Cortes Internacionais. 
O ideário de preservação ambiental atualmente instalado no mundo, só pode ser visualizado, tendo em vista uma obrigação delegada do povo aos seus representantes, bem exemplificada pelo jurista lusitano Boaventura de Souza Santos:

"O Estado, sendo embora um sujeito monumental, visa tão-só garantir a segurança da
vida (Hobbes) e da propriedade (Locke) dos indivíduos na prossecução privada dos
seus interesses particulares segundo as regras próprias e naturais da propriedade e do
mercado, isto é, da sociedade civil. Sendo os cidadãos livres e autónomos, o poder do
Estado só pode assentar no consentimento deles e a obediência que lhe é devida só
pode resultar de uma obrigação auto-assumida, isto é, do contrato social." (SOUZA
SANTOS, 2000. p. 237)

O combate à guerra, poluição, machismo, racismo, e todas as formas de discriminação norteiam e nos conduzem a um novo paradigma social, onde se deve escolher entre preservar as condições de vida saudável e o bem-estar ou a busca desenfreada pelas divisas e o desenvolvimento não sustentado.

Esses paradigmas não dizem respeito a um cidadão nacional, mas sim àquele cidadão mundial cosmopolita, que sente os reflexos de políticas públicas incompetentes de todo o mundo, e necessitam cada vez mais de uma gestão integrada de ações dos governos, e da sociedade civil em geral, através de atitudes responsáveis, sobretudo na ótica ambientalista, o que culminará com a proteção à saúde humana, obviamente.

Logo, visando a preservação ambiental e a manutenção do direito à saúde humana, o mundo se organizou e impôs a tutela internacional do meio ambiente, que condensa vários documentos firmados pelos países signatários, Luís Paulo SIRVINSKAS (2003. p.343) leciona sobre o assunto:

\footnotetext{
"Existe um direito internacional do meio ambiente nascendo com inúmeros tratados, convenções, declarações, recomendações, diretrizes, regras e normas protetivas do meio ambiente. Foi em decorrência da intensa degradação ambiental que houve a necessidade de se proteger o meio ambiente em nível mundial. Como essa degradação não possui fronteiras devidamente delimitadas, resolveu-se criar, na esfera internacional, documentos com a finalidade de se combater a poluição transfronteiriça." (SIRVINSKAS, 2003. p.343)
}

Visto isso, a seguir se abordará detalhadamente a evolução jurídico-protetiva internacional do meio ambiente.

Imprescindível destacar que a consciência de preservação ambiental foi realmente despertada a partir da Conferência das Nações Unidas sobre o Ambiente Humano, em 
Estocolmo (Suécia), em 1972, onde foram estabelecidos princípios básicos de um novo ramo do direito: o Direito Ambiental.

Depois de Estocolmo, o mundo escolheu o Rio de Janeiro (Brasil) para sediar a Cúpula da Terra (ECO-92), importantíssimo passo para a humanidade, sobretudo pelo estabelecimento de metas e diretrizes de ação sobre o meio ambiente.

Lindgren Alves comentando sobre a importância da ECO-92 destacou que: "a Conferência de Viena foi para os direitos humanos o que a Rio-92 foi para o meio ambiente... e entre os documentos delas emanados, a Agenda 21, da Conferência do Rio de Janeiro, foi para o meio ambiente e o desenvolvimento, o que a Declaração e o Programação de Ação de Viena, para os direitos humanos." (SIRVINSKAS, 2003. p. 24)

Na mesma linha, a Declaração do Milênio (2000), realizada em Nova Iorque, aprovada pela Assembleia Geral das Nações Unidas, reúne os planos de todos os Estados-Membros da ONU-Organização das Nações Unidas, para melhorar a vida de todos os habitantes do planeta no século XXI.

A Declaração supracitada estabeleceu metas ambientais programáticas até o ano de 2.050 (inclusive quanto ao Protocolo de Kyoto-Japão), além de assuntos relativos a outros ramos dos direitos humanos.

Ainda no campo da tutela internacional do meio ambiente, na África do Sul aconteceu a Rio+10, no ano de 2.002, na cidade de Johanesburgo, que também foi grande avanço para o meio ambiente em termos globais, apesar das críticas de cunho político ao encontro. ${ }^{3}$

Necessário também destacar que a International for Standardization Organization ISO, com sede em Genebra (Suíça), editou normas visando resguardar a qualidade ambiental do processo produtivo das empresas, o ISO - 14.000. (SIRVINSKAS, 2003. p. 348)

\footnotetext{
${ }^{3}$ Noticiou-se no mundo inteiro que a realização da Rio+10 em Johanesburgo, na África do Sul, tiraria o foco principal da Conferência, qual seja, o meio ambiente e a reafirmação e cumprimento da Rio 92, tendo em vista os problemas pelos quais a África passava, principalmente a fome, desfocando a Conferência para essa causa, diferente da precipuamente preconizada.
} 
Édis Milaré, parafraseado por Sirvinskas, cita que na mesma linha de atuação, no Brasil, através da Associação Brasileira de Normas Técnicas - ABNT, que se associou à ISO, impôs-se aos empresários brasileiros regras internacionais de preservação ambiental, como forma de competirem no mercado internacional sempre resguardando a integridade do meio ambiente, o chamado ISO-14.000. (Édis Milaré, RDA, 5:43, jan./mar. 1997, In: SIRVINSKAS, 2003. p. 348.)

Assim, sem exaurir a temática internacionalista, mas apresentando os pontos principais, viu-se que o arcabouço protetivo do meio ambiente é grande e rico, tanto no âmbito nacional, quanto no âmbito internacional, e consiste em essenciais para a proteção da saúde humana, principalmente porque já possui bases sólidas estabelecidas, as quais podem subsidiar e oferecer à proteção da saúde humana argumentos de autoridade!

\section{A SAÚDE HUMANA COMO DIREITO HUMANO FUNDAMENTAL}

Apresentados os conceitos do meio ambiente, assim como do direito ambiental, no âmbito nacional, como também no plano internacional, agora surge a necessidade de afirmação doutrinária da temática da saúde humana, onde a abordagem tende a ocorrer com a conceituação, o histórico e demais noções introdutórias da saúde humana, assim como o fenômeno da constitucionalização desse direito no Brasil em 1.988, aspecto esse fundamental para firmar bases sólidas a despeito das conclusões que se pretende.

De se ressaltar que no estudo completo citado, do qual o presente capítulo ${ }^{4}$ é parte integrante, foi feita uma detida análise acerca da presença do direito à saúde nas Constituições Brasileiras desde a independência do Brasil, em 1.822, até a presente data, período no qual o Brasil teve oito Constituições no total, sendo que em nenhuma das sete Constituições Nacionais

\footnotetext{
${ }^{4}$ SILVA, Paulo César Nunes da. O Direito à Saúde nas Constituições Brasileiras e a Constituição de 88 como Marco na Garantia do Direito à Saúde. Artigo apresentado ao Congresso Internacional de Direitos Humanos. UFMS: 2018. p. 8-12.
} 
anteriores à vigente se percebeu a presença do direito à saúde, por isso o "salto" histórico dado no trabalho, partindo-se diretamente à Constituição Federal de 1.988 para tratar do assunto.

A redemocratização do Brasil após longo período de Governos militares também trouxe ao país uma nova Constituição. E nela, visando impor limites ao período de exceção recente, uma série de direitos sociais foram propositalmente inscritos na Carta Magna de 1.988.

Inaugurando a Constituição Cidadã, assim carinhosamente apelidada pelo Constituinte Ulysses Guimarães, logo em seu artigo $1^{\circ}$ temos a dignidade da pessoa humana como fundamento da República Federativa do Brasil: “Art. 1 A República Federativa do Brasil, formada pela união indissolúvel dos Estados e Municípios e do Distrito Federal, constitui-se em Estado Democrático de Direito e tem como fundamentos: (...) III - a dignidade da pessoa humana."

A despeito da importância do Direito à Saúde a todos os nacionais ou estrangeiros que aqui vivem, a Constituição também fez questão de prever o Princípio da beneficência em seu bojo, sendo a promoção do bem comum objetivo fundamental da República Federativa do Brasil: “Art. $3^{\circ}$ Constituem objetivos fundamentais da República Federativa do Brasil: (...) IV - promover o bem de todos, sem preconceitos de origem, raça, sexo, cor, idade e quaisquer outras formas de discriminação."

A prova de que a saúde é um direito fundamental é a sua previsão constitucional, onde o mesmo é tratado como direito social: “Art. $6^{\circ}$ São direitos sociais a educação, a saúde, a alimentação, o trabalho, a moradia, o transporte, o lazer, a segurança, a previdência social, a proteção à maternidade e à infância, a assistência aos desamparados, na forma desta Constituição.” (grifou-se)

É certo que até a promulgação da Ordem Constitucional vigente, o Estado Brasileiro não se responsabilizava pela saúde da maioria de sua população, saúde pública, de modo que deixava as pessoas não abrangidas pela Previdência Social e que não possuíam condições financeiras de contratar serviço de saúde privado à mercê da caridade realizada pelas famosas Santas Casas de Misericórdia. (PINHEIRO, 2012, p. 173). 
José Afonso da Silva, espantado com a omissão da previsão do direito à saúde nos documentos constitucionais anteriores aduz:

É espantoso como um bem extraordinariamente relevante à vida humana só agora é elevado à condição de direito fundamental do homem. E há de informar-se pelo princípio de que o direito igual à vida de todos os seres humanos significa também que, nos casos de doença, cada um tem direito a um tratamento condigno de acordo com o estado atual da ciência médica, independentemente de sua situação econômica (...). (SILVA, 2011, p. 308).

Complementando a informação de que o Direito à Saúde é um direito fundamental, já descrito no artigo $6^{\circ}$, o Constituinte melhor explicou o teor desse direito social à saúde, fazendo prever inclusive as frentes de atenção desse direito social, chamado de direito da seguridade social: Art. 194. A seguridade social compreende um conjunto integrado de ações de iniciativa dos Poderes Públicos e da sociedade, destinadas a assegurar os direitos relativos à saúde, à previdência e à assistência social.

Após, vê-se que a seguridade social se desmembra em três distintas frentes, quais sejam, saúde, previdência social e assistência social, necessária a ênfase à saúde, cerne do ensaio, o que é feito no artigo 196, in verbis: Art. 196. A saúde é direito de todos e dever do Estado, garantido mediante políticas sociais e econômicas que visem à redução do risco de doença e de outros agravos e ao acesso universal e igualitário às ações e serviços para sua promoção, proteção e recuperação.

A essencialidade do direito à saúde fica ainda mais clara quando da leitura do artigo 197, que destaca os serviços de saúde como de relevância pública: Art. 197. São de relevância pública as ações e serviços de saúde, cabendo ao Poder Público dispor, nos termos da lei, sobre sua regulamentação, fiscalização e controle, devendo sua execução ser feita diretamente ou através de terceiros e, também, por pessoa física ou jurídica de direito privado.

Na sequência, no artigo 198 tem-se a organização do direito à saúde como sendo uma rede, a qual se nominou Sistema Único de Saúde-SUS, concebida como uma rede regionalizada e hierarquizada.

Nas palavras de SERRANO (2009, p. 35), a despeito da extensa previsão constitucional do direito à saúde, os quais não garantidos na plenitude de imediato após a promulgação da Constituição Cidadã, destaca que o surgimento dos primeiros direitos sociais 
sempre esteve ligado às normas de efeitos programáticos, que traçavam diretrizes a serem buscadas pelo Estado, sem, contudo, qualquer traço de obrigatoriedade, deixando de proporcionar ao beneficiário o respectivo direito subjetivo ou qualquer outro medicamento de exigibilidade.

No entanto, mesmo que inicialmente apenas como normas de caráter programático, ao direito à saúde não é admissível que essa característica possa criar obstáculos ao cidadão na cobrança de ações que visem o cumprimento desses direitos por parte do Poder Público, vide o longo período de ausência desse direito nas Constituições anteriores. "O fato de uma ou outra norma se referir a uma legislação futura não lhes retira a condição de direito fundamental do sujeito, apenas impõe um dever aos órgãos públicos de agir para melhor concretização desses direitos (...)" (QUEIROZ, 2011, p. 59).

Assim, é a Constituição de 1.988 um marco, ponto de partida, desse direito, na qual além da previsão do próprio direito à saúde, tem-se o Capítulo voltado para a higidez do meio ambiente, com o qual a proteção do direito à saúde terá maior completude, já que detém apelo público mundial, além de estrutura internacional de proteção, tendo o poder de elevar a saúde para um patamar superior de proteção!

Ainda nessa senda, da efetividade do direito à saúde, destacando o papel inovador e progressista na Carta de 1.988, SARLET (2012, passim) faz relevante crítica sobre essa classificação ainda adotada por muitos autores. Para o ilustre professor, os direitos fundamentais não devem ser considerados meros enunciados sem força normativa, limitados a proclamações de boas intenções que poderão ou não ser concretizadas, dependendo única e exclusivamente da boa vontade do Poder Público, omisso desde a independência do Brasil, portanto a vinculação da saúde ao meio ambiente tem um papel fantástico para dar maior efetividade à sua garantia, muitas vezes abstrata à norma.

No mesmo raciocínio, Maria do Socorro Azevedo de QUEIROZ (2011, p. 66) defende que diferentemente das normas programáticas, as quais não tem aplicabilidade direta de seus fins, os direitos fundamentais, indistintamente, possuem aplicabilidade imediata, mesmo que no caso dos direitos prestacionais, exijam maior empenho do Estado e da sociedade. 
Neste ponto, vale destacar Salazar e Grou: quando falam que (...) a correta interpretação das normas constitucionais programáticas impõe a conclusão de que delas se extrai, autonomamente, força jurídica e vinculante, ou seja, um grau de eficácia que impõe atribuições aos respectivos destinatários, além de permitir a invocação dos direitos sociais que abrigam de modo amplo e sólido. (SALAZAR; GROU, 2009, p. 27).

Lapidando, as autoras invocam o disposto no art. $5^{\circ}, \S 1^{\circ}$, da Constituição Federal: “As normas definidoras dos direitos e garantias fundamentais têm aplicação imediata", e realçam a intrínseca ligação entre o direito à saúde e a dignidade da pessoa humana, fator que "lhe confere eficácia e justiciabilidade imediatas" (SALAZAR; GROU, 2009, p. 28).

A característica como direito fundamental é redobrada a cada previsão constitucional, e o legislador destacou isso ainda mais quando previu atribuições outras ao Sistema Único de Saúde-SUS na Constituição aniversariante, especificamente em seu artigo 200, e seus oito incisos.

A Constituição Federal, inédita e primorosa também teve o cuidado de abordar o caráter complementar da iniciativa privada no âmbito da saúde pública, sobretudo ante a reconhecida não onipresença do Poder Público no campo da saúde: Art. 199. A assistência à saúde é livre à iniciativa privada. $\S 1^{\circ}$ As instituições privadas poderão participar de forma complementar do sistema único de saúde, segundo diretrizes deste, mediante contrato de direito público ou convênio, tendo preferência as entidades filantrópicas e as sem fins lucrativos.

Na parte final do capítulo destinado às definições do direito à saúde a Constituição Federal de 1.988 tratou de algumas generalidades do funcionamento do Sistema Único de Saúde-SUS, especificamente no artigo 199, tais como proibição de destinação de verbas públicas despropositadamente a instituições privadas (com fins lucrativos), proibição a participação de capital estrangeiro na assistência à saúde no Brasil, e por fim a previsão de uma política nacional de doação de órgãos e tecidos.

Como se viu acima a Constituição Federal de 1.988 previu um rol completo de dispositivos protetores e garantidores do direito à saúde, os quais, apesar de num primeiro momento foram (ou são) tratados como meras normas programáticas, ou seja, não exercitáveis de imediato pelos cidadãos, se constituem como Direito Humano, Fundamental. 
Ainda assim, visando conferir a tais normas, as que garantem o direito à saúde humana, maior aplicabilidade e efetividade, já que se trata de um Direito Fundamental, cuja proteção é dever de todos, sobretudo do Poder Público, é preciso a análise conjunta desse direito à saúde com as normas protetivas do meio ambiente, pois estas são abundantes tanto no âmbito nacional, quanto internacional, e possuem ampla estrutura de proteção, além do forte apelo da educação ambiental para a criação de uma ética ambiental capaz de transformar a preservação do meio ambiente em regra consuetudinária capaz de melhorar a saúde humana.

\section{A NECESSÁRIA INTERFACE ENTRE A PROTEÇÃO DO MEIO AMBIENTE E DA SAÚDE HUMANA}

Igualmente, e já conglobando os conceitos até então trazidos, promover a interface de ambos conceitos, meio ambiente e saúde humana, de modo a destacar a interdisciplinaridade pertinente entre os temas, assim como a possibilidade de maior proteção aos direitos analisados e protegidos conjuntamente, é preceito que se busca com a investigação, e agora fica muito mais evidente.

A esse respeito, lapidar e lógico é a análise específica dos Princípios de Direito Ambiental da Prevenção e/ou Precaução, além do Princípio do Não Retrocesso Social em matéria ambiental, os quais se apresentam como importantes instrumentos protetivos previstos no direito ambiental, estando, portanto, no foco da análise.

Primeiramente, analisando o princípio precaução e/ou prevenção, necessariamente se deve entender sobre os riscos que colocam o meio ambiente em xeque, e para isso importante é o conceito da Professora Elza BOITEUX (2008. p. 508) quando fala que "a avaliação do progresso técnico deve considerar os riscos e benefícios que a intervenção humana pode acarretar para o presente e para o futuro da sociedade".

E segue a destacada Jurista a respeito do risco: "o risco apresenta-se constante na vida moderna e nas sociedades de massa. Assim, quando ele ultrapassa a esfera particular para atingir a esfera do bem comum, a intervenção normativa revela-se o principal instrumento para 
eliminá-lo ou para mantê-lo em níveis aceitáveis” BOITEUX (2008. p. 509), relegando ao direito ambiental a missão de mitigar ou excluir esses riscos potencialmente nocivos ao meio ambiente.

A adoção de medidas preventivas de preservação ao meio ambiente é questão de saúde pública, já que o meio ambiente perfaz o entorno dos seres humanos, sendo que sua higidez é condição essencial da sadia qualidade da vida humana, algo propalado pela própria Constituição Federal no artigo 225, que trata do meio ambiente, sendo recorrente também nas decisões judiciais das Cortes Superior e Suprema do Brasil, portanto no Poder Judiciário Brasileiro. ${ }^{5}$

Assim, providencial é a disposição legal, no âmbito do direito ambiental, do Princípio da Precaução e/ou da Prevenção, isso para garantir a integridade, como já dito.

A Professora Elza BOITEUX (2008. p. 509-510) trata desses Princípios com relevante destaque, inclusive no tocante à nomenclatura (Precaução e/ou Prevenção):

\begin{abstract}
“(...) Antes mesmo de a ciência poder afirmar que algo causa prejuízo, a simples suspeita deve conduzir à suspensão do ato. Para garantir a preservação do meio ambiente, a atividade que ocasiona danos ou riscos para a população deve submeterse aos princípios da prevenção e da precaução. O princípio da prevenção implica na adoção de medidas antes da ocorrência de um dano concreto. Adota-se a prevenção para evitar danos cujas causas são bem conhecidas, com a finalidade de, pelo menos, "minorar significativamente os seus efeitos". O termo "Vorsorge" ("precaução"), que gerou a expressão "Vorsorgeprinzip" ("princípio da precaução"), foi usado pela primeira vez na Alemanha, em 1971, em um programa ambiental do Governo federal. Nos atos internacionais esse princípio foi afirmado explicitamente, pela primeira vez, em 1987, numa conferência internacional sobre o Mar do Norte; a sua forma mais conhecida, no entanto, é aquela adotada na Declaração do Rio, de 1992. O princípio da prevenção foi reformulado na Declaração do Rio, dando origem ao denominado princípio da precaução, que foi aprovado nos seguintes termos: Princípio 15 - De modo a proteger o meio ambiente, o princípio da precaução deve ser amplamente observado pelos Estados, de acordo com suas capacidades. Quando houver ameaça de danos sérios ou irreversíveis, a ausência de absoluta certeza científica não deve ser utilizada como razão para postergar medidas eficazes e economicamente viáveis para prevenir a degradação ambiental."
\end{abstract}

E segue a Jurista explicando de forma mais clara a relevância do Princípio da Prevenção e/ou Precaução: “A Conferência das Nações Unidas sobre o Meio Ambiente e o Desenvolvimento de 1992, também denominada ECO-92, consignou vinte e sete princípios,

\footnotetext{
${ }^{5}$ O Supremo Tribunal Federal reconheceu, em Sessão Plenária, a prevalência do direito à saúde sobre o de exercer atividade econômica, na Medida Cautelar na Ação Direta de Inconstitucionalidade n. 3.540/DF, Sessão Plenária, relator Ministro Celso de Mello, decisão por maioria em $1^{\circ}$ de setembro de 2005, transcrição parcial da ementa: "A atividade econômica não pode ser exercida em desarmonia com os princípios destinados a tornar efetiva proteção ao meio ambiente”. In: BOITEUX (2008. p. 509)
} 
tendo estes por finalidade estabelecer as bases para o desenvolvimento sustentável. Considerado o mais relevante dentre eles, o "Princípio da Precaução"”' (BOITEUX. 2010. p. $510)$.

Noutra parte, com ressalvas a parte, acerca do Princípio do Não Retrocesso Social, nos filiamos à corrente que entende que não há um Princípio do Não Retrocesso Ambiental autônomo, mas sim o Princípio do Não Retrocesso Social, da seara dos Direitos Humanos, que abarcaria a matéria ambiental, seguindo a fala da Professora Elza BOITEUX (2008. p. 507), adepta dessa corrente, acerca do não retrocesso social ela destaca que: "O legislador não pode, por via de novas regras constitucionais, suprimir direitos fundamentais. Eles são irreversíveis. Esta garantia decorre da concepção do sistema de direitos humanos que consagra a evolução da consciência ética coletiva."

Nessa ótica, a fim de explicar essa ressalva, necessário se debruçar na temática específica do Princípio do Não Retrocesso Social, onde a previsão de cláusulas abertas e os direitos constitucionais implícitos no sistema constitucional nacional fizeram eclodir a proibição do retrocesso social como princípio.

No art. $5^{\circ}, \S 2^{\circ}$ da Constituição Federal tem-se que "os direitos e garantias expressos nesta Constituição não excluem outros decorrentes do regime e dos princípios por ela adotados, ou dos tratados internacionais em que a República Federativa do Brasil seja parte.”, fazendonos crer ser o rol de direitos do regime constitucional brasileiro meramente exemplificativo no tocante aos direitos humanos, com a clara adoção de direitos implícitos.

Na sequência, ainda a fim de exemplificar o surgimento do Princípio do Não Retrocesso Social, tem-se as chamadas Cláusulas Pétreas, previstas no art. 60, §4 $, \mathrm{IV}, \mathrm{CF} / 88$, e a proibição do retrocesso social:

“Art. 60. A Constituição poderá ser emendada mediante proposta: I - de um terço, no mínimo, dos membros da Câmara dos Deputados ou do Senado Federal; II - do Presidente da República; III - de mais da metade das Assembléias Legislativas das unidades da Federação, manifestando-se, cada uma delas, pela maioria relativa de seus membros. (...) $\S 4^{\circ}$ Não será objeto de deliberação a proposta de emenda tendente a abolir: I - a forma federativa de Estado; II - o voto direto, secreto, universal e periódico; III - a separação dos Poderes; IV - os direitos e garantias individuais.” 
Importante destacar que o Brasil, paralelamente à previsão constitucional, assinou o Protocolo de San Salvador, datado de 1988, instituído como instrumento adicional à Convenção Americana sobre Direitos Humanos de 1969 (nominada de Pacto de San José da Costa Rica), onde se recepcionou, textualmente, o Princípio da Proibição do Retrocesso Social ou da aplicação progressiva dos direitos sociais.

Dessa forma, qualquer tentativa de supressão ou mutação prejudicial aos direitos sociais, já garantidos por meios legais e político-sociais, é expressamente proibida pela citada Norma Internacional, a qual integrada ao Direito Pátrio, nos termos do art. 60, da CF/88 supracitado.

De acordo, portanto, com o Direito Internacional dos Direitos Humanos - cujas normas, incorporadas pelo Estado brasileiro, possuem plena eficácia e aplicação -, evidenciase também, por esse prisma jurídico, a impossibilidade de supressão ou redução dos Direitos Sociais consagrados no Ordenamento Constitucional Pátrio, reforçando-se a concepção de estarem abrigados estes direitos no núcleo de elementos essenciais postos à margem das iniciativas reformistas.

Assim, considerando que a normativa internacional é plenamente adotada pelo Brasil, com a sua incorporação ao Direito Pátrio, passando a integrar o sistema jurídico nacional (Declaração Universal dos Direitos Humanos de 1948; Pactos Internacionais dos Direitos Civis e Políticos e dos Direitos Sociais, Econômicos e Culturais, de 1966; Convenção Americana sobre Direitos Humanos, de 1969; Protocolo de São Salvador, de 1988; Declaração de Direitos Humanos de Viena, de 1993), igualmente o foi em termos do não retrocesso social.

Na mesma senda, no entanto em matéria ambiental, igualmente a concepção contemporânea dos direitos humanos foi introduzida por diversos documentos e normas internacionais, os quais já presentados anteriormente, estabelecendo nesse campo também a universalidade, a indivisibilidade e a interdependência dos Direitos Humanos (em todas as suas dimensões), não se permitindo sua compartimentalização, separação, hierarquização ou supressão, isso como expressão da essencialidade da dignidade da pessoa humana em todas as suas projeções, seja no campo social, seja no campo ambiental, enfim, em todos os ramos dos direitos humanos. 
Lívia CAMPELLO (2014. p. 266-267) bem explica o Princípio do Não Retrocesso

Social em matéria ambiental, o qual ela chama de Princípio da Não Regressão, assim como a importância do direito ambiental para proteção da saúde humana:

\begin{abstract}
"O meio ambiente é um valor supremo da sociedade internacional contemporânea e passou a compor na construção histórica dos direitos humanos a categoria de terceira dimensão, com fundamento na solidariedade entre os indivíduos. Enquanto direito humano, o meio ambiente pode ser considerado uma extensão do direito à vida sob dois enfoques, seja como condição da própria existência e saúde humana, como também a partir da noção de dignidade humana, concretizada na qualidade de vida das pessoas. Michel Prieur explica que a proteção jurídica do meio ambiente, voltada ao progresso da humanidade e à incessante busca pela melhoria das condições de vida, não pode ser ameaçada por atitudes que ensejam o recuo do Direito Ambiental ${ }^{6}$. Nesse sentido, o autor lista, como possíveis ameaças de retrocesso: a) ameaças políticas: a vontade demagógica de simplificar o direito leva à desregulamentação e, mesmo, à deslegislação em matéria ambiental, visto o número crescente de normas jurídicas ambientais, tanto no plano internacional como no plano nacional; b) ameaças econômicas: a crise econômica mundial favorece os discursos que reclamam menos obrigações jurídicas no âmbito do meio ambiente, sendo que, dentre eles, alguns consideram que essas obrigações seriam um freio ao desenvolvimento e à luta contra a pobreza; c) ameaças psicológicas: a amplitude das normas em matéria ambiental constitui um conjunto complexo, dificilmente acessível aos não especialistas, o que favorece o discurso em favor de uma redução das obrigações do Direito Ambiental. Na mesma linha de preocupação, Antônio Herman Benjamin30 aduz que: [...] se mostra incompatível com a pós-modernidade, que enfatiza a dignidade da pessoa humana, a solidariedade e a segurança jurídica das conquistas da civilização, transformar direitos humanos das presentes gerações e garantias dos interesses dos nossos pósteros num ioiô legislativo, um acordeão desafinado e imprevisível, que ora se expande, ora se retrai."
\end{abstract}

Por fim, utilizando-se da fala do Professor Emérito da Universidade de Limoges (UNILIM - França), Michel Prieur, especificamente no Colóquio sobre o princípio da proibição de retrocesso ambiental - 29 de março de 2012, tem-se que "em face dessas ameaças de regressão, os juristas ambientais devem reagir de maneira dura, com fundamento em argumentos jurídicos inquestionáveis. A opinião pública, uma vez alertada, não admitiria

\footnotetext{
${ }^{6}$ Sobre o "risco de regressão" no direito ambiental, leciona Prieur: "Para descrever este risco de "não retrocesso', a terminologia utilizada pela doutrina ainda é hesitante. Em certos países, menciona-se o princípio do standstill. É o caso da Bélgica. Na França se utiliza o conceito do Efeito Cliquet (catraca) ou regra 'Cliquet' antirretorno. Alguns autores falam em 'intangibilidade' de certos direitos fundamentais ou de cláusula de "status quo". Em inglês, encontra-se a expressão 'eternity clause' ou 'entrenched clause', em espanhol 'prohibicion de regresividad o de retroceso', em português 'proibição de retrocesso'. Utilizaremos, pois, afórmula do 'princípio da não regressão', para demonstrar que não é uma simples cláusula ou mera regra, mas sim um verdadeiro princípio, é também a expressão de um dever de não regressão imposto ao Poder Público. Utilizando-se da 'não regressão' no que tange ao meio ambiente, procura-se sobrelevar os degraus na proteção do meio ambiente e que os progressos legislativos consistem numa segurança 'progressiva' da proteção mais elevada possível do meio ambiente no interesse coletivo da humanidade, da mesma maneira que existe a progressão dos direitos humanos." (PRIEUR, Michel. O Princípio da "Não Regressão" no coração do Direito do Homem e do Meio Ambiente. In: Revista Novos Estudos Jurídicos. Vol. 17, n. 1, p. 07.).
} 
retrocessos na proteção ambiental, visto que isso implica ameaca à própria saúde humana" (grifou-se).

Visto, portanto, que a interdependência do meio ambiente e da saúde humana é indiscutível, e sua análise conjunta possibilita uma maior e mais efetiva proteção aos seres humanos.

\section{CONSIDERAÇÕES FINAIS}

Chegando-se às considerações finais do ensaio, é certo afirmar que qualquer dano causado ao meio ambiente provoca prejuízos à saúde humana, onde "a existência de um é a própria condição da existência do outro" (GRANZIERA e DALLARI, 2005. p. 607), motivo esse de que os seres humanos devem viver em plena e total harmonia com o meio ambiente, pois isso é condição de sua própria sobrevivência!

Sabendo-se que várias são as formas que o meio ambiente influencia a saúde humana, dentre as quais destaque à contaminação da água, a poluição do ar, a emissão de ruídos acima no permitido, as condições de saúde e segurança do trabalho, entre outros usos nocivos do meio ambiente (natural, artificial, cultural e do trabalho), tem-se que a utilização das regras jurídicas do direito ambiental para a proteção da saúde humana é premissa, o que fica claro com a releitura crítica do artigo 225, da Constituição Federal do Brasil, onde se prevê que: "Todos têm direito ao meio ambiente ecologicamente equilibrado, bem de uso comum do povo e essencial à sadia qualidade de vida, impondo-se ao Poder Público e à coletividade o dever de defendêlo e preservá-lo para as presentes e futuras gerações" (grifou-se).

Nota-se que o dispositivo em foco é categórico ao afirmar que o meio ambiente ecologicamente equilibrado é essencial à sadia qualidade de vida, ou seja, à própria saúde. (GRANZIERA e DALLARI, 2005. p. 607)

Também no plano nacional, ainda na Constituição Federal do Brasil, mas em seu artigo 200, estão descritas algumas atribuições do Sistema Único de Saúde-SUS, dentre as quais se 
menciona a fiscalização de alimentos, bebidas e água para o consumo humano (inciso VI) e a colaboração na proteção do meio ambiente (inciso VIII), temas indissociáveis afetos à saúde e ao meio ambiente.

Ainda concluindo, pertinente citar a Lei $\mathrm{n}^{\circ}$ 6.938/81, que estabeleceu a Política Nacional do Meio Ambiente, amplamente citada no ensaio, que tem por objetivo, entre outros, a preservação, melhoria e recuperação da qualidade ambiental favorável à vida e, via de consequência, favorável à saúde humana, visando assegurar condições ao desenvolvimento socioeconômico (ecodesenvolvimento) e à proteção da dignidade humana (artigo $2^{\circ}$ ).

A referida Lei vai além, e define poluição como a degradação da qualidade ambiental resultante das atividades que direta ou indiretamente prejudiquem a saúde, a segurança e o bem-estar da população (artigo $3^{\circ}$, inciso III, alínea "a") (grifou-se).

Noutra banda, mas no mesmo sentido, compulsando a legislação afeta à saúde, cabe citar a Lei $\mathrm{n}^{\circ}$ 8.080/90, que regula em todo país as ações e serviços de saúde. Na referida Lei, além de consignar o meio ambiente como um dos vários fatores condicionantes para a saúde (artigo $3^{\circ}$ ), estão previstas uma série de ações integradas relacionadas à saúde, meio ambiente e saneamento básico.

Sabe-se, portanto, que o Direito Ambiental, que visa a manutenção de um perfeito equilíbrio nas relações do homem com o meio ambiente, possui alicerces próprios (princípios), que são decorrentes não apenas de um sistema normativo ambiental, mas também do sistema de direito positivo em vigor (MIRRA, 1996. p. 53), sendo que o estudo analisou justamente em alguns pontos desse alicerce, e destacou-os.

A despeito dos vários princípios apresentados no trabalho, maior destaque foi dado aos Princípios da Prevenção e/ou Precaução, e do Não Retrocesso Social, em matéria ambiental, todos supedâneos à efetiva proteção da saúde humana.

A rigor da importância desses princípios para a saúde humana, Paulo Affonso de Leme Machado explica que "a implementação do princípio da precaução não tem por finalidade imobilizar as atividades humanas. Não se trata da precaução que tudo impede ou que em tudo vê catástrofes ou males. O princípio da precaução visa à durabilidade da sadia qualidade de 
vida das geracões humanas e à continuidade da natureza existente no planeta" ((grifou-se). MACHADO, 2002. p. 54)

Essa conclusão, apesar de óbvia, decorre do fato de que eventuais danos à saúde podem ser irreversíveis e devastadores, e a utilização dos princípios da precaução e da prevenção é de fundamental importância para a salvaguarda da vida, bem esse mais essencial do ser humano, tanto que a Agência Europeia do Ambiente ${ }^{7}$ emitiu nota a respeito desse posicionamento:

\begin{abstract}
"Um ambiente limpo é essencial para a saúde e bem-estar das pessoas. No entanto, as interacções entre a saúde humana e o ambiente são muito complexas e difíceis de avaliar, o que torna a utilização do princípio de precaução especialmente útil. Os impactos na saúde mais conhecidos estão relacionados com a poluição atmosférica, a fraca qualidade da água e as condições sanitárias insuficientes. Pouco mais se sabe sobre os efeitos das substâncias químicas perigosas na saúde. O ruído é um problema de saúde e ambiental emergente. As alterações climáticas, a destruição da camada de ozono estratosférico, a perda de biodiversidade e a degradação dos solos também podem afectar a saúde humana."
\end{abstract}

Nacional e Internacionalmente a proteção à saúde humana é intrinsicamente ligada à proteção do meio ambiente, tanto que diversos são os pactos e tratados que contém posições normativas protetivas à vida, assim, justo também destacar à guisa de considerações finais a importância do Princípio do Não Retrocesso Social, especificamente em matéria ambiental, pois, como viu-se, ele proíbe qualquer involução em termos de proteção a direitos humanos já consolidados e garantidos.

Neste ponto, utilizando de importante lição da Professora Lívia CAMPELLO (2014. p. 277), ela destaca que "por sua vez, o princípio da não regressão decorre da percepção do meio ambiente como um direito humano, intrinsecamente ligado à dignidade humana. Da natureza progressiva de tais direitos deduz-se que sua proteção não pode ser vítima de retrocessos, e o Direito Internacional do Meio Ambiente não se furta a essa regra. Tal entendimento, inclusive, no caso de conflito de regras internacionais ambientais, orienta a prevalência daquela que conferir a mais ampla proteção ao meio ambiente.”, fazendo-nos crer ainda mais que a interdependências das temáticas saúde e meio ambiente é umbilical.

Assim, a despeito do postulado da dignidade da pessoa humana, trazido como fundamento da República Federativa do Brasil e dos Direitos Humanos, consiste em uma

\footnotetext{
${ }^{7}$ Disponível em: https://www.eea.europa.eu/pt/themes/human. Acesso em: 15 Out 2018.
} 
característica inerente ao ser humano e dispõe que o homem não pode, de nenhum modo, ser utilizado como meio para alcance de outro objetivo, devendo esses interesses serem contemporizados, de modo a equilibrar o direito à saúde e o desenvolvimento econômico, a tão propagada sustentabilidade, sendo essa uma das missões do direito ambiental por meio de seus princípios, garantir a saúde humana de quaisquer afrontas, sobretudo preventivamente, não permitindo qualquer involução nesse sentido.

\section{REFERÊNCIAS BIBLIOGRÁFICAS}

AGÊNCIA EUROPÉIA DO AMBIENTE. Disponível em: https://www.eea.europa.eu/pt/themes/human. Acesso em: 15 Out. 2018.

ANTUNES, Paulo de Bessa. Direito ambiental, 4a ed. Rio de Janeiro: Lumen Juris, 2000.

BARLETTA, Fabiana Rodrigues. O direito à saúde da pessoa idosa. Saraiva, 2010.

BENJAMIM, Antônio Herman. Princípio da proibição do retrocesso ambiental. In: Colóquio sobre o princípio da proibição do retrocesso ambiental. Brasília: Senado Federal, 2012.

Antônio Herman. Constitucionalização do ambiente e ecologização da Constituição brasileira. In: CANOTILHO, José Joaquim Gomes; LEITE, José Rubens Morato (coords). Direito Constitucional Ambiental brasileiro. São Paulo: Saraiva, 2007, p. 57/58.

BOITEUX, E. A. P. C. (2008). Educação e valores ambientais. Revista Da Faculdade De Direito, Universidade De São Paulo, v.103, p. 503-516. Disponível em: https://doi.org/10.11606/issn.2318-8235.v103i0p503-516. Acesso em 6 Out. 2018.

E. A. P. C. (2010). O princípio da solidariedade e os direitos humanos de natureza ambiental. Revista Da Faculdade De Direito, Universidade De São Paulo, v. 105, p. 509-533. Disponível em: https://doi.org/10.11606/issn.2318-8235.v105i0p509-533. Acesso em 25 Set. 2018.

BONAVIDES, Paulo; MIRANDA, Jorge; AGRA, Walber de Moura (Coord.). Comentários à Constituição de 1988. Rio de Janeiro: Forense, 2009.

BRASIL. Constituição (1988). Constituição da República Federativa do Brasil. Brasília, 1988. Disponível

em < http://www.planalto.gov.br/ccivil 03/constituicao/constituicao.htm $>$. Acesso em: 15 Ago. 2018. 
Brasília, 1981.

Lei n. 6.938 de 1981. Dispõe sobre a Política Nacional do Meio Ambiente. em < http://www.planalto.gov.br/ccivil 03/LEIS/L6938.htm>. Acesso em: 15 Ago. 2018.

. Lei n. 9.795 de 1999. Dispõe sobre a educação ambiental, institui a Política Nacional de Educação Ambiental. Brasília, 1999. Disponível em <http://www.planalto.gov.br/ccivIl 03/LEIS/L9795.htm>. Acesso em: 15 Ago. 2018.

. Lei n. 8.080 de 1990. Dispõe sobre as condições para a promoção, proteção $e$ recuperação da saúde, a organização e o funcionamento dos serviços correspondentes. Brasília, 1990.

Disponível em < http://www.planalto.gov.br/ccivil 03/leis/L8080.htm>. Acesso em: 15 Ago. 2018.

CAMPELLO, Lívia Gaigher Bósio; SOUZA, Maria Claudia da Silva Antunes de; e PADILHA, Norma Sueli (Org.). Direito ambiental no século XXI: efetividade e desafios. Belo Horizonte: Arraes Editores, 2014.

CANOTILHO, José Joaquim Gomes. Direito Constitucional e Teoria da Constituição. $7^{\mathrm{a}}$ ed. Coimbra: Editora Almedina, 2003.

CAPRA, Fritjof. A teia da vida: uma nova compreensão científica dos sistemas vivos. Trad. Newton Roberval Eichemberg. 10. reimp. São Paulo: Cultrix, 2006.

DALLARI, Dalmo de Abreu. Direitos humanos e cidadania. São Paulo: Moderna, 1998.

GRANZIERA, Maria Luiza Machado; DALLARI, Sueli Gandolfi. Direito Sanitário e Meio Ambiente. In: PHILIPPI JR., Arlindo: ALVES, Alaor Caffé (Editores). Curso Interdisciplinar de Direito Ambiental. Barueri-SP: Manole, 2005.

PINHEIRO, Naíde Maria. Estatuto do Idoso Comentado. Campinas, SP: Servanda Editora, 2012.

PRIEUR, Michel. Princípio da proibição do retrocesso ambiental. In: Colóquio sobre o princípio da proibição do retrocesso ambiental. Brasília: Senado Federal, 2012.

QUEIROZ, Maria do Socorro Azevedo de. Judicialização dos Direitos Sociais Prestacionais: A efetividade pela Interdependência dos Direitos Fundamentais na Constituição Brasileira. Curitiba: Juruá, 2011.

MACHADO, Paulo Affonso de Leme, Direito Ambiental Brasileiro. 10 ${ }^{\text {a }}$ ed. São Paulo: Malheiros Editores, 2002.

MENDOSA, Douglas. Tensões em torno da efetivação do direito à saúde no Sistema Único de Saúde. 2.007. Disponível em <http://www.teses.usp.br/teses/disponiveis/8/8132/tde05032007-232241/pt-br.php>. Acesso em: 13 Mar. 2018. 
MIRRA, Alvaro Luiz Valery. Princípios Fundamentais do direito ambiental. Revista de Direito Ambiental n 2, São Paulo, 1996, RT.

SALAZAR, Andrea Lazzarini; GROU, Karina Bozola. A defesa da saúde em juízo. São Paulo: Editora Verbatim, 2009.

SARLET, Ingo Wolfgang. Dignidade da pessoa humana e direitos fundamentais na Constituição Federal de 1988. 9ª Edição. Porto Alegre: Livraria do Advogado, 2012.

SERRANO, Mônica de Almeida Magalhães. O Sistema Único de Saúde e suas Diretrizes Constitucionais. $1^{\text {a }}$ ed. São Paulo: Verbatim, 2009.

SILVA, José Afonso da. Direito Ambiental Constitucional. 4. ed. São Paulo: Malheiros, 2003. Malheiros, 2011. José Afonso da. Curso de Direito Constitucional Positivo. 34ª ed. São Paulo:

SILVA, Paulo César Nunes da. O Direito à Saúde nas Constituições Brasileiras e a Constituição de 88 como Marco na Garantia do Direito à Saúde. Artigo apresentado ao Congresso Internacional de Direitos Humanos. UFMS: 2018.

SIRVINSKAS, Luís Paulo. Manual de direito ambiental. São Paulo: Saraiva, 2003.

SOUZA SANTOS, Boaventura de. Pela mão de Alice: o social e o político na pósmodernidade. 7. ed. São Paulo: Cortez, 2000.

SUPREMO TRIBUNAL FEDERAL. RE $271286 \quad A g R / R S$. Disponível em: < http://www.stf.jus.br>. Acesso em: 20 Mar. 2018.

Submetido em: 20/05/2019

Aceito em: 17/09/2019 